\title{
MODEL INVESTIGATIONS INTO THE INFLUENCE OF RENATURALIZATION ON SEDIMENT TRANSPORT
}

\author{
W. Bechteler, H.-J. Vollmers, S. Wieprecht \\ Institut für Wasserwesen \\ Universität der Bundeswehr München \\ D - 85577 Neubiberg
}

\section{Abstract}

Efforts have recently been made to renaturalize the WeiBach River which had previously been regulated in a schematic, monotonous manner. During the last flood period an agglomeration of sediment occurred, which may provoke an overtopping of the dams. In a hydraulic model with movable bed (scale 1:20) the existing conditions and possible improvements were studied in order to prevent agglomerations. Furthermore, fundamental investigations were made with regard to the influence of constructional steps on sediment transport and water levels.

1. Introduction

1.1 General Remarks

Most natural rivers are in a sensitive state of hydraulic-sedimentological balance, which is defined by mutual influences of water and solids. Lowland rivers show in general a "continuous" transport behaviour throughout the year. Depending on the discharge, more or less material is being transported. 
In the case of alpine rivers the transport behaviour is characterized by different factors of influence. As the bed material consists of rather coarse grain diameters bed load transport will only start at great bed shear velocities. In order to set the bed material into motion high discharges are necessary, i.e. only flood events are actual transport events. Up to 80 or $90 \%$ of the total annual transport volume may be transported in the course of a single flood wave.

\subsection{Problem Description}

Recently the attempt has been made to renaturalize the last section of the Weissach River before it flows into Lake Tegernsee. This part had been previously regulated in a schematic monotonous way. During the last flood period an agglomeration of sediment has occurred, which may provoke an overtopping of the dams. In a hydraulic model with movable bed (scale 1:20) the existing conditions and possible improvements were studied in order to prevent agglomerations. Furthermore fundamental investigations were made about the influence of obstructions on sediment transport and water levels.

\section{Similarity Considerations}

\subsection{General Remarks}

The knowledge of the physical basis of sediment transport is still so fragmentary that it is not possible to develop a generally acceptable calculation approach. Owing to the practical importance of the phenomenon, however, there are quite a number of more or less empirical formulas, whose bases and ranges of application differ from each other. Therefore their calculation results may also differ considerably. 
Tab. 1 presents a list of the total annual sediment transport in the Loisach River (Upper Bavaria) calculated according to several authors. The actual total annual sediment transport has been found to be about $30000 \mathrm{~m}^{3}$ by averaging the dredged material of several years.

\begin{tabular}{|c|c|c|c|c|}
\hline Transport Model & $\begin{array}{l}\text { water } \\
\text { disch } \\
\text { start } \\
{[\mathrm{m}]}\end{array}$ & $\begin{array}{l}h \text { and } \\
\text { for } \\
\text { otion } \\
{\left[\mathrm{m}^{3} / \mathrm{s}\right]}\end{array}$ & $\begin{array}{l}\text { days per } \\
\text { year with } \\
\text { transport } \\
\text { [days] }\end{array}$ & $\begin{array}{c}\text { annual } \\
\text { total } \\
\text { sediment } \\
\text { transport } \\
{\left[\mathrm{m}^{3}\right]}\end{array}$ \\
\hline $\begin{array}{l}\text { Meyer-Peter, Müller, } 1949 \\
\text { Laursen, 1958 } \\
\text { Bishop, e.a., } 1965 \\
\text { Pernecker, Vollmers, } 1965 \\
\text { Engelund, Hansen, } 1967 \\
\text { Graf, Acaroglu, 1968 } \\
\text { Ackers, White, 1973 } \\
\text { Ranga Raju, e.a., 1981 } \\
\text { Karim, Kennedy, TLTM, } 1983\end{array}$ & $\begin{array}{l}0.87 \\
0.99 \\
0.00 \\
0.49 \\
0.00 \\
0.00 \\
0.72 \\
1.03 \\
0.69\end{array}$ & $\begin{array}{r}20.05 \\
25.65 \\
0.00 \\
6.04 \\
0.00 \\
0.00 \\
13.60 \\
28.20 \\
12.40\end{array}$ & $\begin{array}{r}173 \\
109 \\
365 \\
363 \\
365 \\
365 \\
264 \\
94 \\
279\end{array}$ & $\begin{array}{rr}29 & 648 \\
32 & 331 \\
92 & 430 \\
39 & 222 \\
36 & 973 \\
32 & 626 \\
23 & 718 \\
9 & 206 \\
8 & 666\end{array}$ \\
\hline
\end{tabular}

Tab. 1: Annual Total Sediment Transport Loisach, Gauge Schlehdorf, VOLLMERS, 1992

In contrast to other branches of science the answering of practical questions is the main object in the engineering sciences. This is true especially in the case of hydraulic constructions! About 100 years ago hydraulic engineers "invented" the physical model, as already GALILEI realised the difficulties in calculating the course of waters (contrary to the movement of planets!). Up to the present day such models (in the meantime extended to mathematical ones) are part of the hydraulic engineer's standard tools in answering practical questions. Hydraulic models with movable beds belong to the highest category of difficulties and can only be successfully operated in laboratories with excellent equipment and great experience. The greatest problem is the conversion of model test results into natural values and vice versa (VOLLMERS, 1989). The creation of similarity between nature and model is time-consuming and physically not exactly feasible.

Finally it has to be pointed out that the major part of the present knowledge about sediment transport comes from investigations performed on simplified physical models. 
2.2 Model Similarity

The movable bed physical model of the Weissach River was built at a geometric scale of $1: 20$ in the hydromechanics laboratory of the federal Armed Forces University Munich at Neubiberg. All geometric and hydraulic values were calculated according to FROUDE's similarity law, which means that processes dominated by gravitation and inertia are represented similarly in nature and model. Frictional forces may be neglected in this case due to the coarse grain material of the river bed.

The choice of the model sand was guided by the idea to keep the part of the suspended material as low as possible, because the geometrical reduction would have contradicted natural conditions. Therefore an almost uniform sand was selected, the mean diameter $\left(d_{m} \approx d_{65} \approx 0.85 \mathrm{~mm}\right)$ of which corresponds well with the geometric reduction of the $d_{m}-v a l u e ~ o f$ the natural bed material $\left(d_{m}=14.3 \mathrm{~mm}\right)$. Fig. 1 contains the grain distribution curves of the natural and the model materials as well as the theoretical curve corresponding to the model scale $1: 20$.

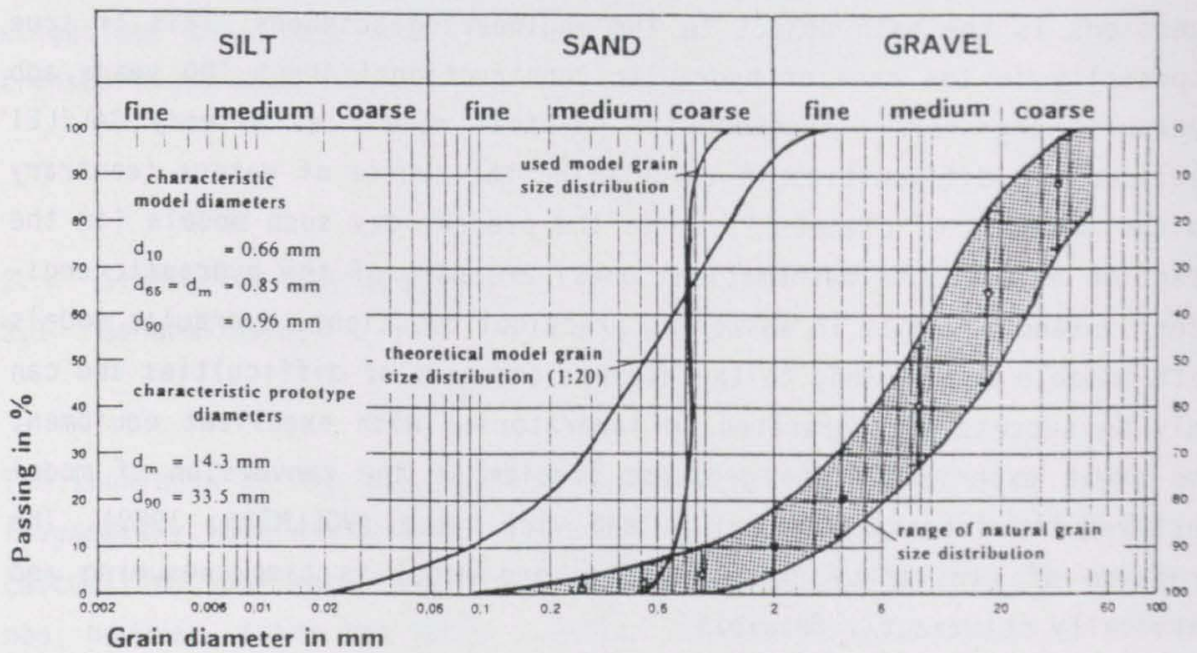

Fig. 1: Grain size distribution curves: natural grain, used model grain, theoretical model grain 


\section{Model Set-up \\ 3.1 Model Description}

The model consists of two equally long sections that are connected by a hinge. It is supported by two I-shaped steel girders, the elevation of which can be adjusted to any slope desired for different investigations. The simplified trapezoidal cross-section of the river has been placed into the frame of a rectangular cross-section. The lateral embankments are made of sheet iron. Roughness is simulated by coarse sands glued onto the surface. A bed material ground layer of $10 \mathrm{~cm}$ thickness prevents the ground plate from being washed free in erosion ranges. Two circular metal rods, one on each side of the flume, serve as rails for the measuring carriage. Fig. 2 shows a model cross-section and Fig. 3 presents a plan view of the model.

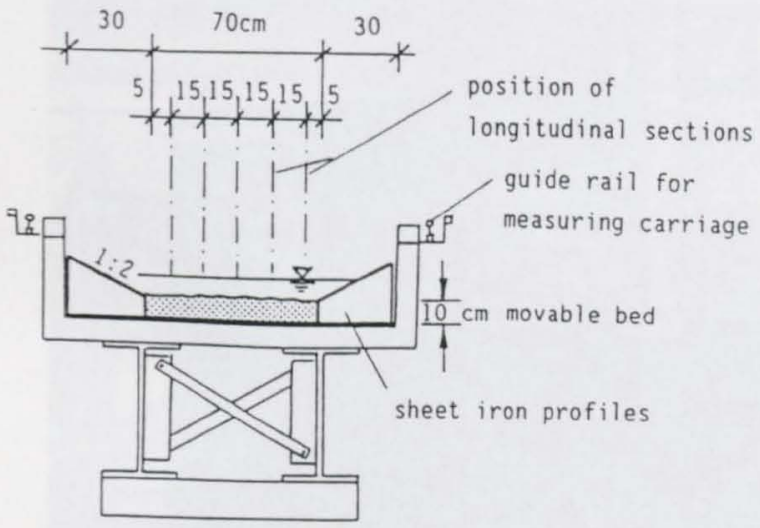

Fig. 2: Schematic cross-section of the model

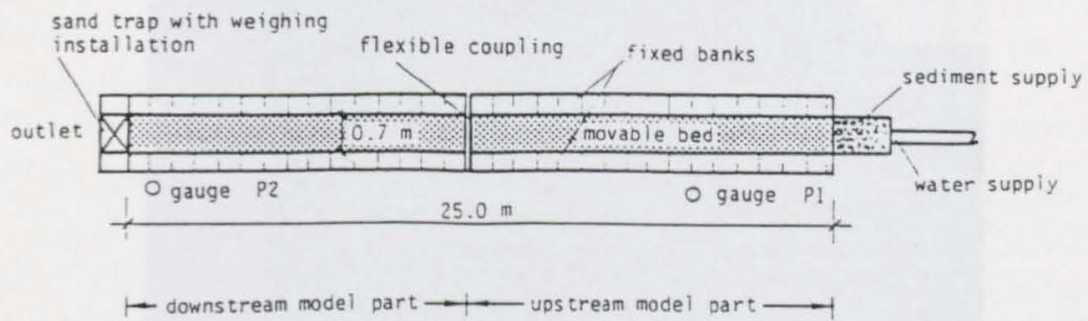

Fig. 3: Plan view of the model 


\subsection{Operating and Measuring Installations}

The water supply for the model comes out of an elevated reservoir. Discharge regulation is controlled by an inductive flowmeter. Both are connected to the computer. At the model outlet the water pours down into a basement reservoir where it is pumped back into the elevated supply reservoir.

The water level at the model outlet is controlled by a nearby gauge and may be adjusted by an overflow plate. A second gauge is installed at the beginning of the measuring range, about $5 \mathrm{~m}$ away from the inflow and the sand supply. Measuring instruments are so-called vibrating water level followers (Delft) with an accuracy of \pm 0.5 to $1 \mathrm{~mm}$.

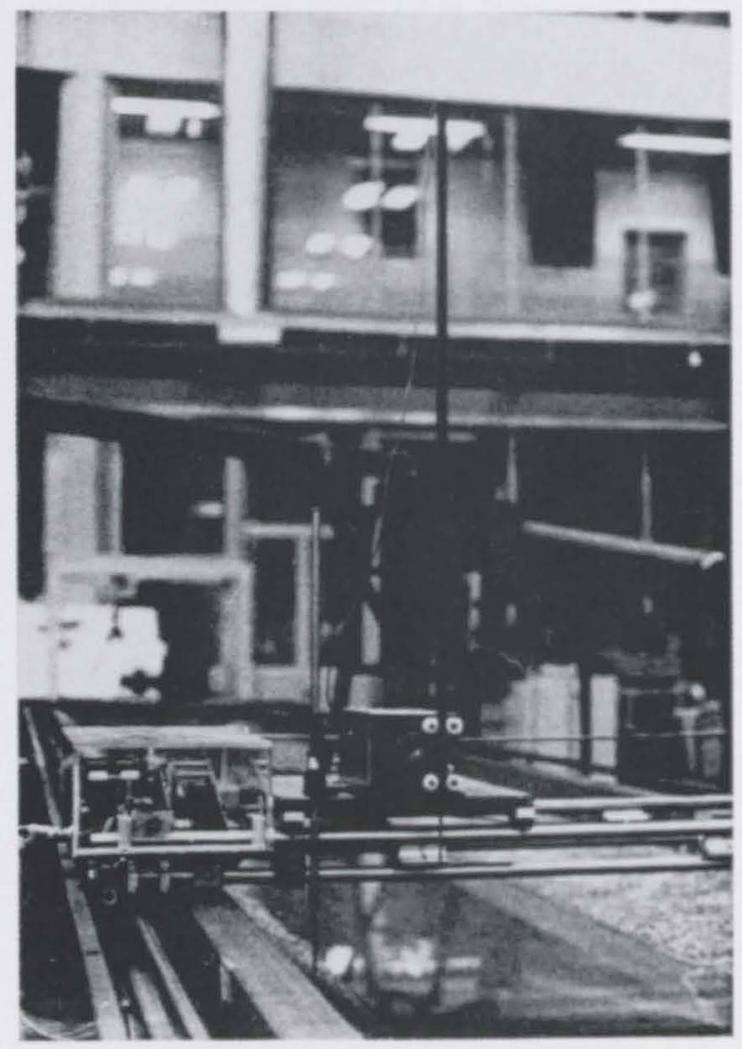

Fig. 4: Profile follower 
For the assessment of river bottom changes longitudinal profiles were registered both before and after a test (positions of these profiles are given in Fig. 3). Registration was performed using a Delft profile follower (Fig. 4) with a vertical adjustment velocity of up to $50 \mathrm{~cm} / \mathrm{s}$ and an accuracy of \pm 1 to $1.5 \mathrm{~mm}$.

The input comes as a sand-water-mixture out of a plexiglass tube with a vertical slot, which is opened at a constant predefined speed and thus provides a constant inflow of material per unit of time (Fig. 5).

The collection device (sand trap) at the model outlet is a balance pan suspended from a pressure/strain transducer (Fig. 6). At certain variable time intervals signals are transmitted to the computer.

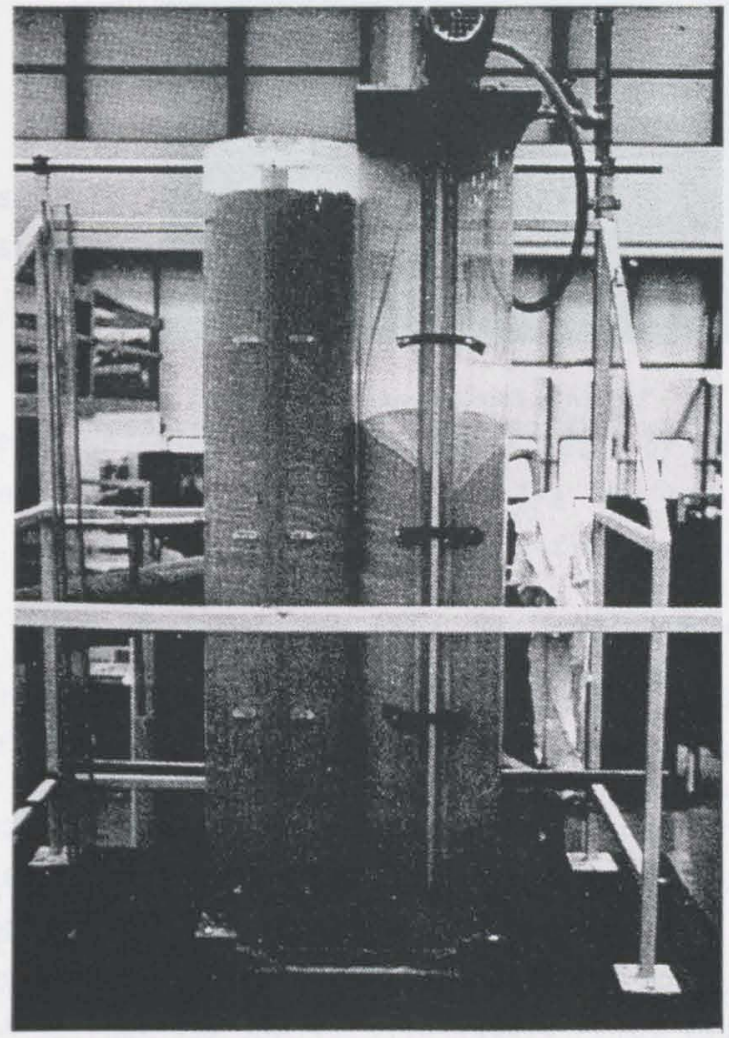

Fig. 5: Input device for wet sand 


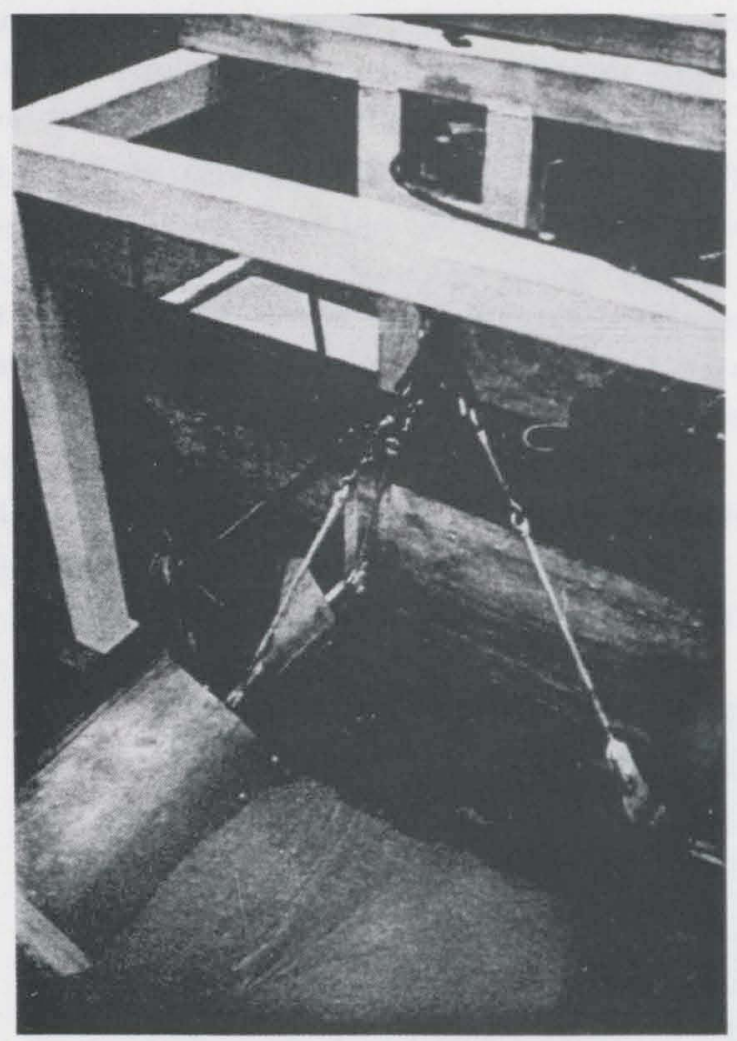

Fig. 6: Model outflow with bed load measuring device

\section{Model Tests and Results}

\subsection{Tests without Constructional Elements}

Tests without constructional elements served as the basis of comparison with the others that were to be performed later on and to contain different variations. At the beginning tests with constant discharges provided a transport-discharge relation (Fig. 7). They have been executed for three different slopes $\left(S_{I}=0.002, S_{I I}=0.004\right.$ and $\left.S_{I I I}=0.006\right)$. In order to allow systematic comparisons regarding the sediment transport, the transport rates obtained in the calibration tests were used as input rates for the tests with constructional elements. 


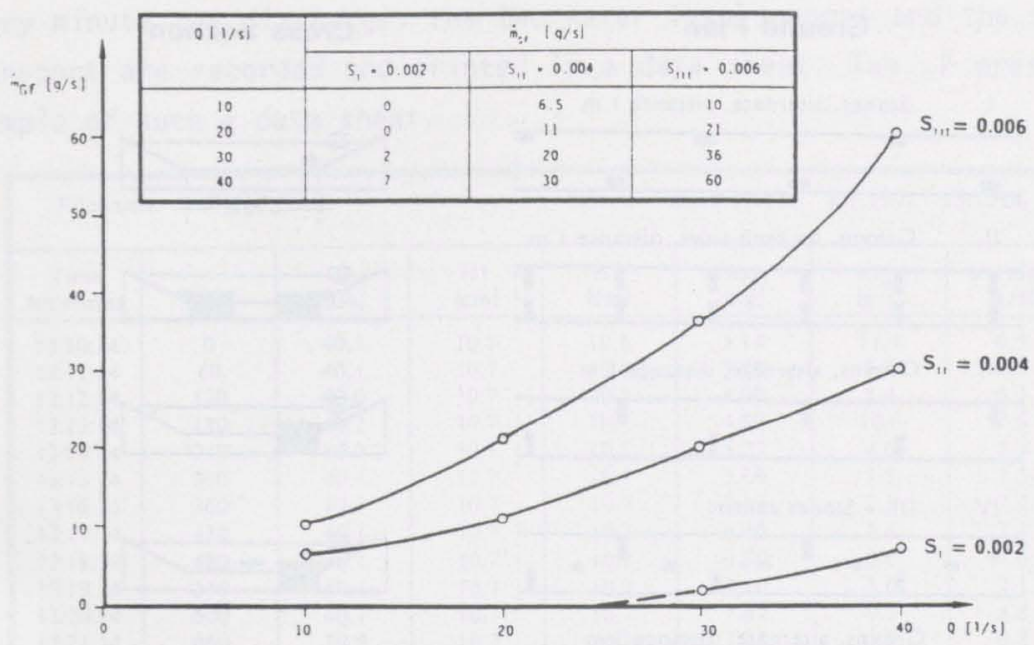

Fig. 7: Transport-discharge diagram for all three slopes

\subsection{Tests with Constructional Elements}

\subsubsection{Test Programme and Performance}

The test programme comprised investigations of ten series of different arrangements of constructional elements, each of which was to be tested for three discharges $(Q=10 \mathrm{l} / \mathrm{s}, 20 \mathrm{l} / \mathrm{s}, 40 \mathrm{l} / \mathrm{s})$, three slopes $(S=$ $0.002,0.004,0.006)$ and one characteristic grain diameter $\left(d_{c h}=0.85\right.$ $\mathrm{mm})$.

Altogether this led to 90 different tests. Fig. 8 presents all variations of arrangements of constructional elements schematically in plan view and cross-sectional elevation (series I through $\mathrm{X}$ ).

As actual construction works use boulders of about $1 \mathrm{~m}$ side length, all constructional elements were modelled using stones of 5 to $6 \mathrm{~cm}$ diameter, which corresponds to the 1 : 20 scale. Boulders and groynes are put directly upon the movable bed, whereas levelled and elevated ground sills are placed on the fixed solid ground plate, which lies $10 \mathrm{~cm} 10$ wer. Thus it can be checked whether some of the elements change their positions owing to erosion and scouring. 


\section{Ground Plan}

1. Stones. alternate. distance $1 \mathrm{~m}$

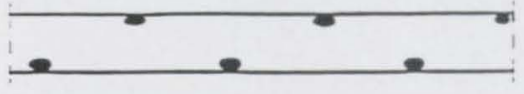

I1. Groyns, on both sides, distance I m

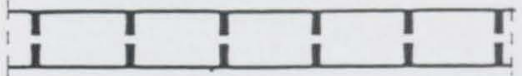

III. Groyns, alternate, distance I m

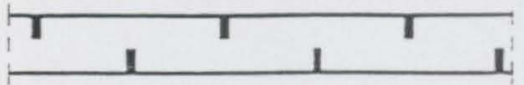

IV. III. + Stones centric
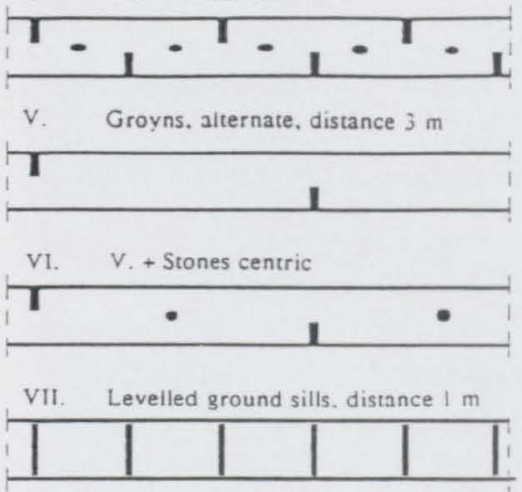

VIII. Ground sills, distance I m

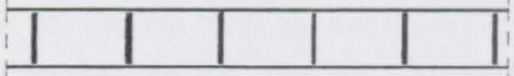

IX. Levelled ground sills. distance $2.8 \mathrm{~m}$
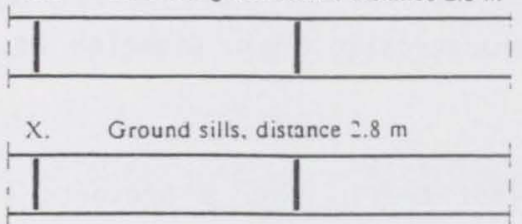

\section{Cross Section}
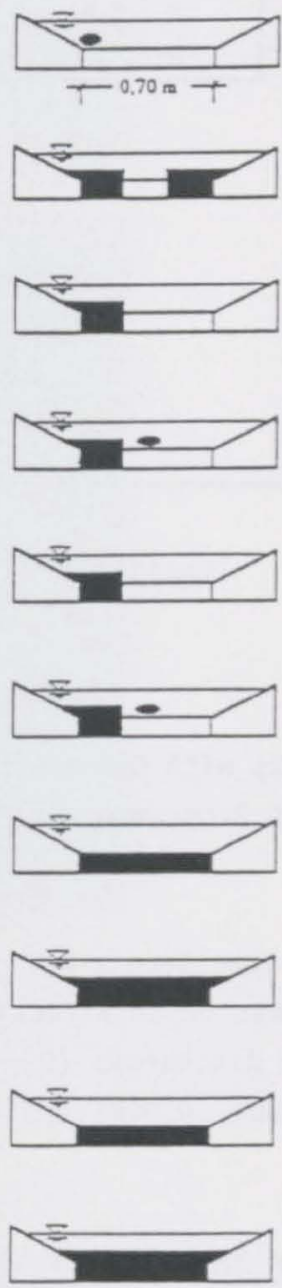

Fig. 8: Plan view and cross-section of different constructional measures (schematic)

The execution of a test is similar with and without arranging constructional elements. Bed profiles were registered before the test after levelling the flume bed and after test execution. Comparing both registrations allows the assessment of bottom changes. Their differences show where erosion or sedimentation, occurred in the $16 \mathrm{~m}$ measuring range. 
Every minute the discharge, the two water level gauges and the sediment transport are recorded and printed in a data sheet. Tab. 2 presents an example of such a data sheet.

\begin{tabular}{|c|c|c|c|c|c|c|c|}
\hline Filename: & \multicolumn{3}{|c|}{ IVEI089.DAT } & \multicolumn{2}{|c|}{ Start of measurement: } & 8.1 .1992 & 13:10:06 \\
\hline $\begin{array}{c}\text { Time } \\
\text { hh:mm:ss }\end{array}$ & [sec] & $\begin{array}{c}Q \\
u / s]\end{array}$ & $\begin{array}{c}\mathrm{H} 1 \\
{[\mathrm{~cm}]}\end{array}$ & $\begin{array}{c}\mathrm{H} 2 \\
{[\mathrm{~cm}]}\end{array}$ & $\begin{array}{c}\text { mass } \\
{[\mathrm{kg}]}\end{array}$ & $\begin{array}{l}m_{G G} \\
{[g / s]}\end{array}$ & $\begin{array}{c}\text { average } \\
{[\mathrm{g} / \mathrm{s}]}\end{array}$ \\
\hline $13: 10: 14$ & 0 & 40.1 & 10.7 & 10.8 & 3.14 & 11.1 & 6.5 \\
\hline $13: 11: 14$ & 60 & 40.1 & 10.7 & 10.8 & 3.48 & 5.8 & 6.5 \\
\hline $13: 12: 14$ & 120 & 40.0 & 10.7 & 10.8 & 4.00 & 8.4 & 6.7 \\
\hline $13: 13: 14$ & 180 & 40.2 & 10.7 & 10.7 & 4.99 & 16.6 & 7.6 \\
\hline $13: 14: 14$ & 240 & 40.0 & 10.7 & 10.7 & 5.27 & 4.6 & 7.3 \\
\hline $13: 15: 14$ & 300 & 40.1 & 10.7 & 10.7 & 5.69 & 7.2 & 7.3 \\
\hline $13: 16: 14$ & 360 & 40.1 & 10.7 & 10.7 & 6.12 & 7.1 & 7.2 \\
\hline $13: 17: 14$ & 420 & 40.1 & 10.7 & 10.7 & 6.46 & 5.6 & 7.1 \\
\hline $13: 18: 14$ & 480 & 40.1 & 10.7 & 10.7 & 6.80 & 5.6 & 7.0 \\
\hline $13: 19: 14$ & 540 & 40.1 & 10.7 & 10.7 & 7.10 & 5.0 & 7.1 \\
\hline $13: 20: 14$ & 600 & 40.1 & 10.7 & 10.7 & 7.67 & 9.5 & 6.8 \\
\hline $13: 21: 14$ & 660 & 39.9 & 10.7 & 10.7 & 7.78 & 1.9 & 6.8 \\
\hline $13: 22: 14$ & 720 & 40.1 & 10.8 & 10.7 & 8.18 & 6.6 & 6.9 \\
\hline $13: 23: 14$ & 780 & 40.2 & 10.8 & 10.7 & 8.75 & 9.3 & 7.0 \\
\hline $13: 24: 14$ & 840 & 40.1 & 10.8 & 10.7 & 9.28 & 8.9 & 6.9 \\
\hline $13: 25: 14$ & 900 & 40.1 & 10.8 & 10.7 & 9.47 & 3.2 & 6.8 \\
\hline $13: 26: 14$ & 960 & 40.1 & 10.8 & 10.7 & 9.85 & 6.4 & 6.6 \\
\hline $13: 27: 14$ & 1020 & 40.0 & 10.8 & 10.7 & 9.94 & 1.6 & 6.6 \\
\hline $13: 28: 14$ & 1080 & 40.2 & 10.8 & 10.6 & 10.31 & 6.1 & 6.6 \\
\hline $13: 29: 14$ & 1140 & 40.2 & 10.8 & 10.6 & 10.47 & 2.7 & 6.5 \\
\hline \multicolumn{8}{|c|}{ End of measurement: 8.1 .1992} \\
\hline
\end{tabular}

Tab. 2: Data sheet of test WEI089. DAT.Q $=40 \mathrm{l} / \mathrm{s}, \mathrm{S}_{I}=0.002$, Variant II

Column "mGf" shows the transport per minute and column "average" gives the average transport value since the start of the test. The values per minute scatter rather strongly around the quickly stabilized mean value. This is because generally bed load transport is not a uniform process, but rather takes place by thrusts, which is even increased by bed forms moving obliquely to the flume axis.

\subsubsection{Test Evaluation}

The comparison of test series results was made possible by introducing a number characterizing the degree of obstruction caused by the constructional elements. As these elements have different distances the degree 
of obstruction was calculated to be the ratio of "obstructed volume" (Fig. 9 "B") to "unobstructed volume" (Fig. 9 "A"). Reference length is one metre. Thus levelled ground sills have an obstructional degree of $0 \%$, as their crests are at an even level with the bottom elevation, and therefore do not obstruct the cross-sectional area at all.

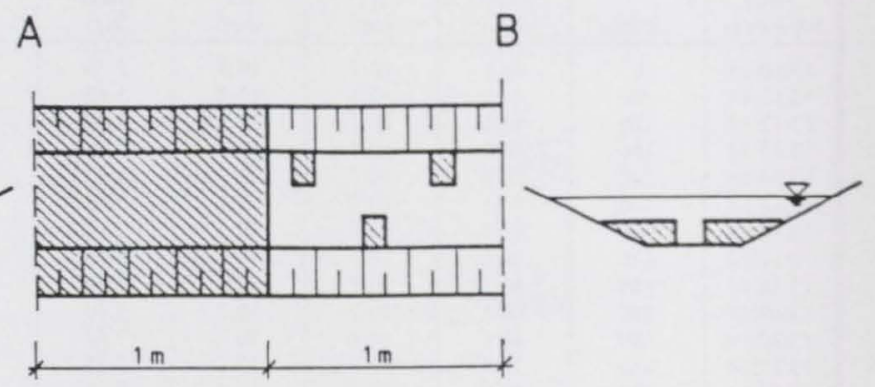

Fig. 9: A: unobstructed volume, B: obstructed volume (schematically) Variant V VI III II VIII

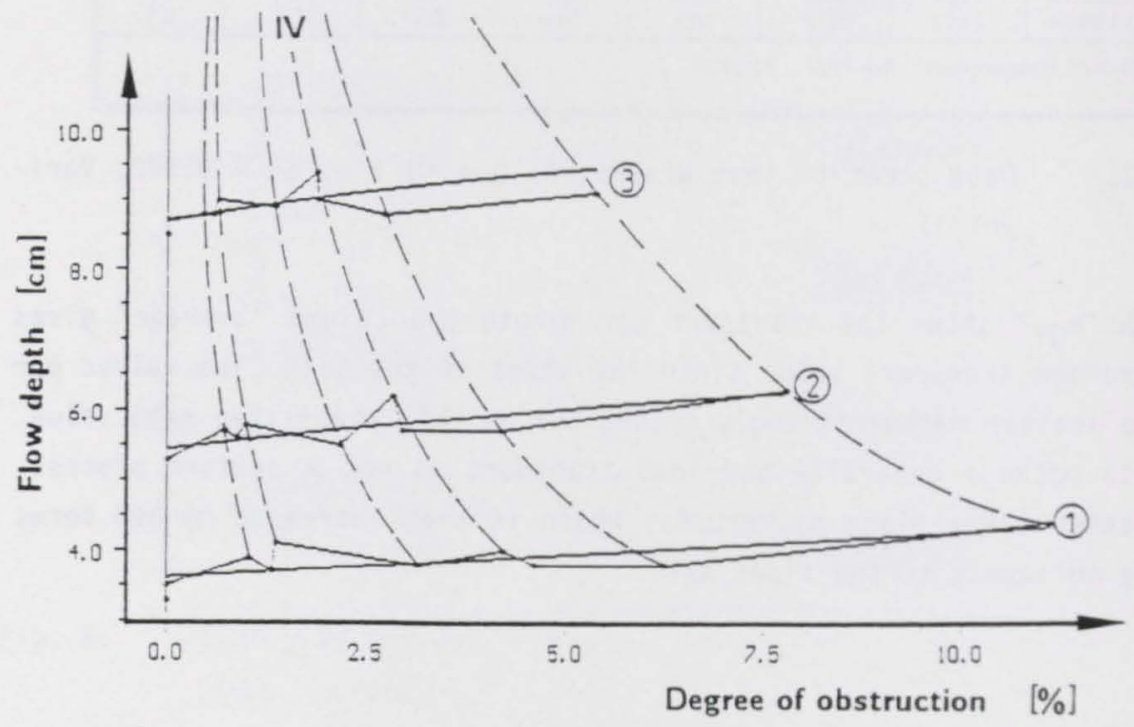

Fig. 10: Changes of flow depths versus degree of obstruction and corresponding fitting curves for slope $\mathrm{S}_{\mathrm{II}}=0.004$ and discharges $Q=10 \mathrm{l} / \mathrm{s}(1), Q=20 \mathrm{l} / \mathrm{s}(2)$ and $Q=40 \mathrm{l} / \mathrm{s}(3)$

The same systematic tendency could be found in all tests performed so far. Water levels increase with an increasing degree of obstruction. Fig. 10 show the results from test with a slope $S_{I I}=0.004$. Measurement 
points in the diagram are connected by a polygonal line. The second degree fitting curves demonstrate the systematic tendency of the measurements. They are not meant to serve as calibration curves for the relation between degree of obstruction and water depth.

Flow depths served to compute velocities and FROUDE numbers as well as MANNING-STRICKLER coefficients.

For increasing degrees of obstruction there is a constant decrease of roughness coefficients, velocities, and FROUDE numbers. This tendency can be recognized for more or less all values calculated. As an example Figs. 11 and 12 show for slope $S_{I I}=0.004$ the dependence of velocities and MANNING-STRICKLER coefficients on the degree of obstruction.

Contrary to tests with fixed bottom and constant roughness, $\mathrm{k}_{S t}$-values do not increase but rather decrease with rising discharge and water level. Flume roughness grows for greater discharges due to bed form shaping. As flow depths are altogether rather low, i.e. between 3 and $11 \mathrm{~cm}$, bed forms have a great influence on roughness. This influence was reduced by increasing water depths.

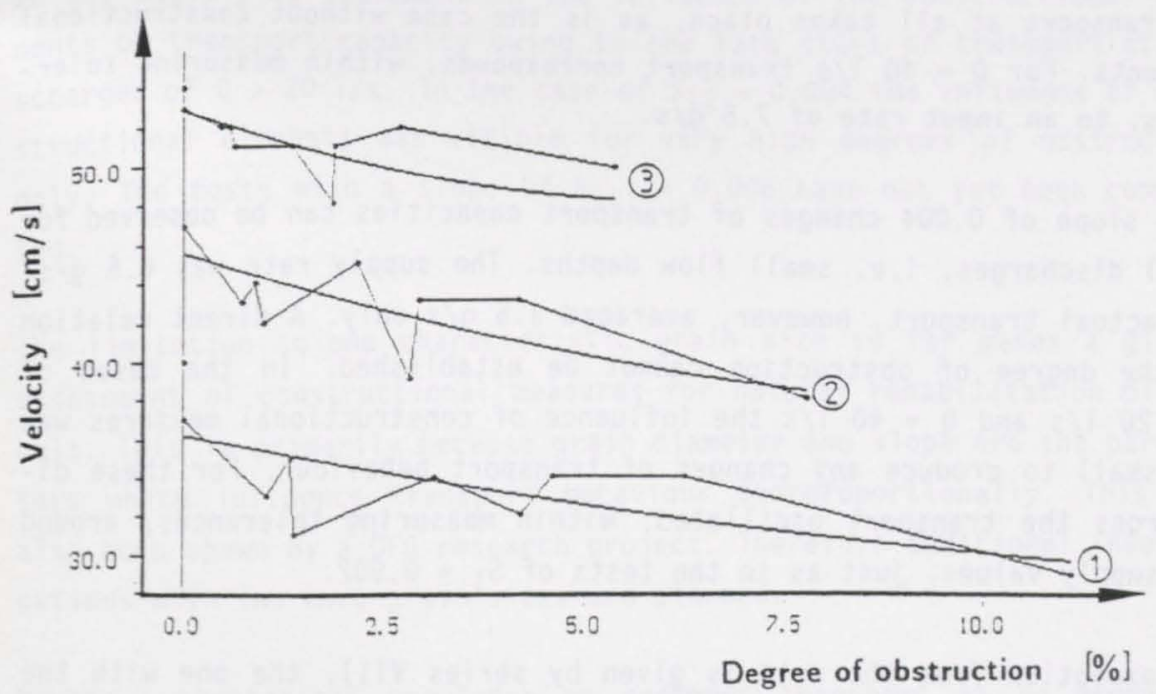

Fig. 11: Changes of velocity versus degree of obstruction and corresponding fitting curves for slope $\mathrm{S}_{\mathrm{II}}=0.004$ and discharges $Q=10 \mathrm{l} / \mathrm{s}(1), Q=20 \mathrm{l} / \mathrm{s}(2)$ and $Q=40 \mathrm{l} / \mathrm{s}$ 


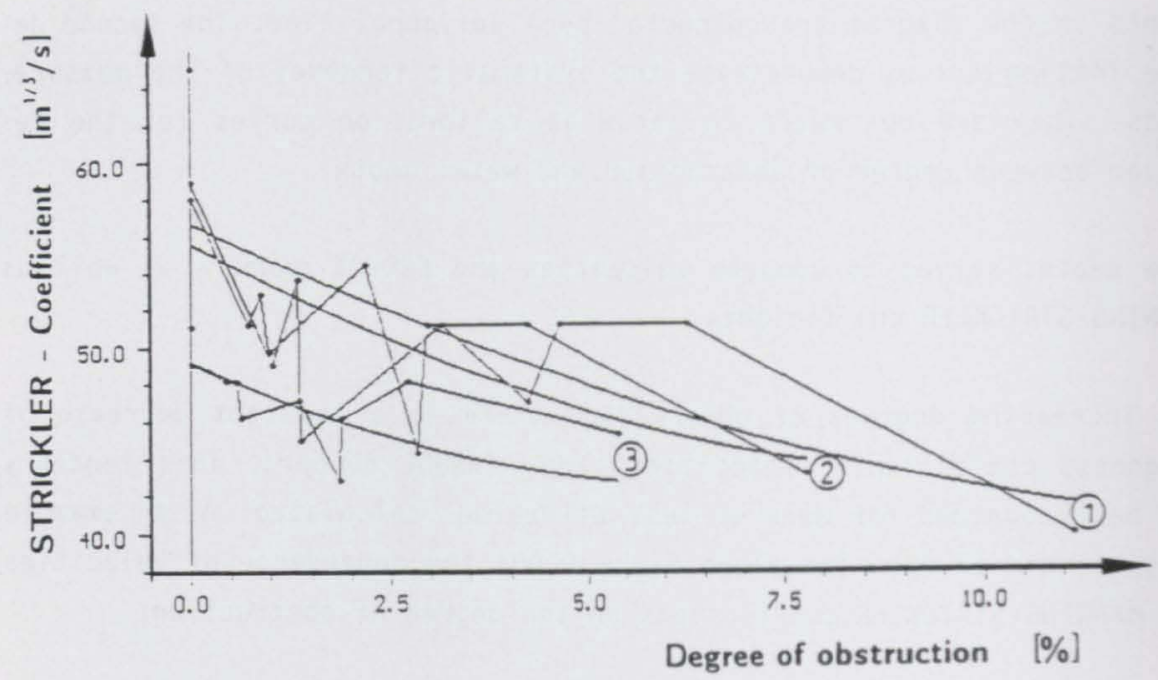

Fig. 12: Changes of roughness coefficients versus degree of obstruction and corresponding fitting curves for slope $\mathrm{S}_{\mathrm{II}}=0.004$ and discharges $Q=10 \mathrm{l} / \mathrm{s}(1), Q=20 \mathrm{l} / \mathrm{s} \mathrm{(2)} \mathrm{and} Q=40 \mathrm{l} / \mathrm{s}$ (3)

Changes of transport behaviour are strongly dependent on slope. A slope of 0.002 does not show any transport changes. For $Q=10 \mathrm{l} / \mathrm{s}$ and $20 \mathrm{l} / \mathrm{s}$ no transport at all takes place, as is the case without constructional elements. For $Q=40 \mathrm{l} / \mathrm{s}$ transport corresponds, within measuring tolerances, to an input rate of $7.5 \mathrm{~g} / \mathrm{s}$.

At a slope of 0.004 changes of transport capacities can be observed for small discharges, i.e. small flow depths. The supply rate was $6.5 \mathrm{~g} / \mathrm{s}$, the actual transport, however, averaged $3.5 \mathrm{~g} / \mathrm{s}$ only. A direct relation to the degree of obstruction cannot be established. In the cases of $Q=20 \mathrm{l} / \mathrm{s}$ and $Q=40 \mathrm{l} / \mathrm{s}$ the influence of constructional measures was too small to produce any changes of transport behaviour. For these discharges the transport oscillated, within measuring tolerances, around the supply values, just as in the tests of $S_{I}=0.002$.

The exception from the rule is given by series VIII, the one with the greatest obstructional degree. All tests show transport values clearly below the ones found at the beginning in the initial test series (Fig. 11). 


\section{Conclusion}

The effects of renaturalisation works on the hydraulic and morphologic equilibrium of a river, can hardly be foreseen. It is therefore necessary to rely on simulations in physical or mathematical models to predict possible effects of constructional steps. The choice of the model type depends on which model is better suited to simulate nature properly.

Calculation procedures already exist to deal with overgrown cross- sections (DVWK Regel $\mathrm{Nr}$. 127). The influence of constructional elements, however, still cannot be described exactly. First investigations on changes of transport capacity have been performed (EILERS, 1990), but have yet to be generalized.

In all test series the same systematic development could be observed. With an increase in the degree of obstruction the water depths also increased, and velocities, FROUDE numbers and roughness coefficients decreased. The results of the investigations on the transport capacity differ considerably. For the slope of 0.002 it is hardly possible to make any satisfying statement on the influence of the constructional elements on transport capacity owing to the late start of transport at discharges of $Q>20 \mathrm{l} / \mathrm{s}$. In the case of $S_{I I}=0.004$ the influence of constructional elements was visible for very high degrees of obstruction only. The tests with a slope of $S_{\text {III }}=0.006$ have not yet been completed.

The limitation to one characteristic grain size so far makes a global assessment of constructional measures for natural rehabilitation difficult. This is primarily because grain diameter and slope are the parameters which influence transport behaviour overproportionally. This has also been shown by a DFG research project. Therefore additional investigations with two more grain sizes are planned.

Nowadays theoretical knowledge on sediment transport is in progress. Nevertheless it is still impossible to generally describe the transport behaviour of a river. Therefore fundamental investigations have yet to be performed in combination with field observations and measurements. 
6. References

BECHTELER $W$.

VOGEL G.

VOLLMERS H. $-\mathrm{J}$.

DIN

DVWK

DVWK

DVWK

EILERS $J$.

VOLLMERS H. $-\mathrm{J}$.

VOLLMERS, H.-J.

ZANKE $U$.
Model Investigations on the Sediment Transport of a Lower Alpine River

Proceedings, International Workshop on Fluvial Hydraulics of Mountain Regions, Trento, Italy, 1989

Deutsche Norm, Hydrologie, Quantitative Begriffe, DIN 4049, Tei1 103

Hydraulische Berechnungen von $\mathrm{Fl}$ ießgewässern DVWK-Merkblatt 220/1991, Verlag Paul Parey, 1991

Geschiebemessungen

DVWK-Regeln 127/1992, Verlag Paul Parey, 1992

Hydraul ic Modelling

DVWK-Bullet in No. 7, Editor H. Kobus, Verlag Paul Parey, 1980

Zur Berechnung offener Gerinne mit beweglicher Sohle und Uferbewuchs

Mitteilungen aus dem Leichtweiß-Institut für Wasserbau, Nr. 106, TU Braunschweig, 1990

The State of the Art of Physical Modelling of Sediment Transport

Sediment Transport Modelling, Proc. International Symposium, New Orleans, 1989

Sediment Transport Equations and Annual Total Load, 5th Int. Symp. on River Sedimentation, Karlsruhe, 1992

Grundlagen der Sedimentbewegung

Springer-Verlag, Berlin Heidelberg, 1982 